\title{
Organizational resilience and social-economic sustainability: COVID-19 perspective
}

\author{
Siddharth Shankar Rai ${ }^{1}$ Shivam Rai ${ }^{2}$. Nitin Kumar Singh ${ }^{3}$
}

Received: 15 August 2020 / Accepted: 9 December 2020 / Published online: 22 January 2021

(c) The Author(s), under exclusive licence to Springer Nature B.V. part of Springer Nature 2021

\begin{abstract}
COVID-19 has affected the global economy like no other crisis in the history of mankind. It forced worldwide lockdown and economic shutdown to the point from where the recovery process has been very difficult. It has affected demand, supply, production and consumption in such a way that the entire economic development cycle has gone to its lowest levels. COVID-19 has also affected the social and economic sustainability structure which has led from one crisis to another and the developing countries have been the worst hit. Economic crisis resulted in unemployment leading to labour migrations, inevitable casualties and rising poverty etc. However, at a certain level, a few industries and organizations have shown resilience with better anticipation and survivability which may lead them to a quicker recovery. The current study aims at presenting a holistic view of organizational resilience which leads to the overall sustainable development. The study considers three aspects of organizational resilience as crisis anticipation, organizational robustness and recoverability. It assesses the impact of the aspects of resilience on social sustainability and economic sustainability. The study uses empirical analysis of primary data which is analysed to verify the hypothesized relationships by using a structural equation modelling approach. The study finds out that predicting the crisis and disruptions, building robustness and recoverability have a positive effect on both the social and economic aspects of sustainability. Findings of the study have their practical implications for industry, researchers and society.
\end{abstract}

Keywords Resilience $\cdot$ Sustainability $\cdot$ Crisis anticipation · Organizational robustness · Social sustainability $\cdot$ Economic sustainability

Nitin Kumar Singh

nitinkumar.singh@marwadieducation.edu.in

Siddharth Shankar Rai

ssrai025@gmail.com

Shivam Rai

shivamrai1990@gmail.com

1 RGSC, Banaras Hindu University, Uttar Pradesh, India

2 Xavier University Bhubaneswar, Odisha, India

3 MEFGI, Rajkot, Gujarat, India 


\section{Introduction}

The world has seen one of the worst crises known to the history of mankind in the form of COVID-19 pandemic which has caused global unrest and devastation to the worldwide economy (Arora et al. 2020; Rajput et al. 2020). Having its contagious nature and health risks, the disease has forced worldwide disturbance such as lockdowns; closure of ports and airports; strict manpower norms; limiting imports and exports and so on (Bherwani et al. 2020; Sharma et al. 2020; Rajput et al. 2020; Gautam 2020). The economic shutdown has downgraded manufacturing, increased layoffs, high unemployment, slowed down demand and reduced industrial profits (Sharma et al. 2020; Gautam and Hens 2020; Rajput et al. 2020). Plenty of industries such as aviation, hospitality, tourism, entertainment and transportation etc. are struggling for survival and many organizations are at the verge of being shut down. However, there have been plenty of organizations which have been resilient enough to be less affected by the pandemic so far and many organizations are recovering faster than others even after being affected. For example, Nestle in India was very much resilient and unaffected during the complete lockdown in India, while other companies suffered losses during the same period (Gupta 2020). Resilience plays a crucial role in the survival of organizations. It is the ability to anticipate, survive in and recover from a turbulent environment with the ability to return to original or an improved state (Chowdhury and Quaddus 2017; Brusset and Teller 2017; Pettit et al. 2013; Christopher and Peck 2004). Resilience has three main aspects - anticipation, avoidance and adjustment which, respectively, focus one predictability, immunity and recovery. Many authors categorise the resilience in two parts as proactive resilience and reactive resilience where proactive refers to the preparedness and reactive refers to the recovery from turbulence (Chowdhury and Quaddus 2017; Sheffi 2005). In the current study, we have adopted a holistic view of resilience which focuses on all three dimensions.

One of the worst hits by the crisis is the sustainability structure of the organizations, especially in emerging countries like Brazil and India (Gautam and Hens 2020). Sustainability focuses on conservation for the future generations and it includes three aspectsenvironment, society and economy which is also called a triple bottom line (TBL) approach. Plenty of research has been done in the context of environmental sustainability worldwide. Social sustainability (which is referred as corporate social responsibility (CSR) by the majority of researchers) and economic sustainability (which focuses on organizational cost reduction through adoption of sustainable practises) have not been very much included by researchers especially in the emerging economies (Tang 2018a, b). However, these two aspects have witnessed worse crisis as society and economy both have been hit and both are trying to recover. A handful of research covering these aspects mainly represents the contexts of developed nations. Even among those studies, the social and economic aspects generally combine with environment either individually or with collective TBL approach. For instance: Barbosa-Póvoa et al. (2018) have observed that sustainability studies still lack in terms of holistic economic assessment and the assessment of environmental and social aspects. It lacks focusing on the measurement of implementing sustainable practises leading to cost minimization or profit maximization. For example, Zhang et al. (2018) have focused on green supply chain management (GSCM) as an indicator of environmental practises and corporate social responsibility (CSR) in their empirical model of sustainable supply chain management (SSCM). They have argued about multidimensional consideration of SSCM; however, their model does not very much explain the economic consideration. Esfahbodi et al. (2016) have considered the environmental performance and cost 
performance in their empirical model. Although the model mainly focuses on the environmental aspects and misses out the social agenda. King and Lenox (2001) have emphasized the environmental performance within the production environment, however, leaving the social and economic issues.

In the current study, we focus on a bi-dimensional approach of social and economic sustainability which is a major concern during the COVID-19 pandemic. To cover the context of an emerging economy, the study has been carried out in India which is among the countries having the fastest virus spread. The major research gaps that emphasize the importance of this study are: first, there is the need for such studies that focus on the holistic assessment of organizational resilience with the inclusion of tri-dimensional assessment in the turbulent situations. Second, there are very few studies that focus on social sustainability and economic sustainability in emerging economies. Third, there is a lack of such studies that combine resilience and sustainability and emphasize on maintaining sustainable values, while recovering from a crisis. Based on the aforementioned gaps the study presents its key objectives as: first, to find out how a resilient structure of the organizations may affect their social and economic sustainability during a global crisis like COVID-19 outbreak. Second, to evaluate the impact of individual dimensions of organizational resilience on social sustainability and economic sustainability. The study, therefore, poses the following research questions: RQ1: What are the parameters to evaluate the different aspects of resilience in the context of the current crisis? RQ2: What are the social and economic aspects of sustainability which is affected in the crisis? RQ3: How can we measure the impact of organizational resilience on social sustainability and economic sustainability?

The study focuses on contributing to both the practitioners and academia in several ways. First, it provides a holistic assessment of organizational resilience which is helpful for the firms in their survivability and recovery process during a crisis. Second, it offers a detailed assessment of social and economic sustainability which are at very risk during a crisis as the organizations tend to overlook them over their survival. Third, the study provides a cause and effect relationship between organizational resilience and its sustainability structure which tries to answer the question that how we can survive and become responsible at the same time. Fourth, the study explores how sustainability and resilience can be beneficial for organizations in the longer run.

\section{Theory and hypothesis}

\subsection{Social: economic sustainability}

Sustainability has emerged as one of the most researched areas in the management which can be confirmed from the day by day increasing research studies as well as corporate practises which also have started integrating the sustainability principles into their operations, while trying the same compliance to sustainable operations across their supply chains worldwide (Qorri et al. 2018). Sustainability is a phenomenon that stresses about the responsible acts of the human being towards the encompassing environment, the society and the future generations (Kates et al. 2001; Clark and Dickson 2003; Clark 2007). Derived from the idea, the researchers, as well as policymakers, strive for a development that caters to the needs of the present society, while it does not hamper the capability of the future generations to meet their requirements (Zhang et al. 2018). Social sustainability also termed as corporate social responsibility (CSR) is a responsible practise voluntarily where 
social concerns are integrated with the organizational operations as well as in the shareholder interactions (Tang 2018a, b). Hence the social sustainability refers to the management of social issues throughout the value chain while ensuring the survival of the organization in the long run (Mani et al. 2016). It addresses social issues and how they are dealt which includes labour conditions, well-being, quality of life, equality, diversity and connectedness within and outside the community among the major concerns (Mani et al. 2018, 2016; Jia et al. 2018). To preserve the social sustainability structure, the organizations need to respect the labour rights which is extended to their job security, fair wages and social security (Mani et al. 2016). During a crisis when organizations are more concerned about their survival which is more in monetary terms, their self-interests conflict with the social interests and their investment in CSR activities reduces (Sajko et al. 2020). The current crisis has forced organizations to reduce their CSR initiatives hence, we consider lay-offs, wage reductions, health and safety issues, hygiene and social distancing, compliance with the government norms and employment generation for local society among our major constructs (Mani et al. 2018, 2016; Zhang et al. 2018; Tang 2018a, b; Qorri et al. 2018; Jia et al. 2018) (see Fig. 1).

There are various aspects of sustainability including the popular social and environmental concerns, however, they are all traced backed to the economic aspect which sustain and stabilizes the other aspects (Manca 2015). Economic sustainability refers to the generation of income for the members of society without exploiting the capital and resources which in turn generated circular effect and stabilizes the economy (Chelan et al. 2018; Spangenberg 2005; Pires et al. 2017). To have this circular effect which stabilizes both economy and society, the organizations must transform their practises towards renewability, reusability, recycling and life cycle costing as well as integrate the cost of wastes, emissions and pollutions etc. in the costing system (Kibert 2016; Zhong and Wu 2015). Cairns and Martinet (2014) have used sustainability accounting to assess the environmental-economic indicators and their role in sustainable growth and overall sustainable improvement. The dimensions of economic sustainability range from sales, market share, operational efficiency, and

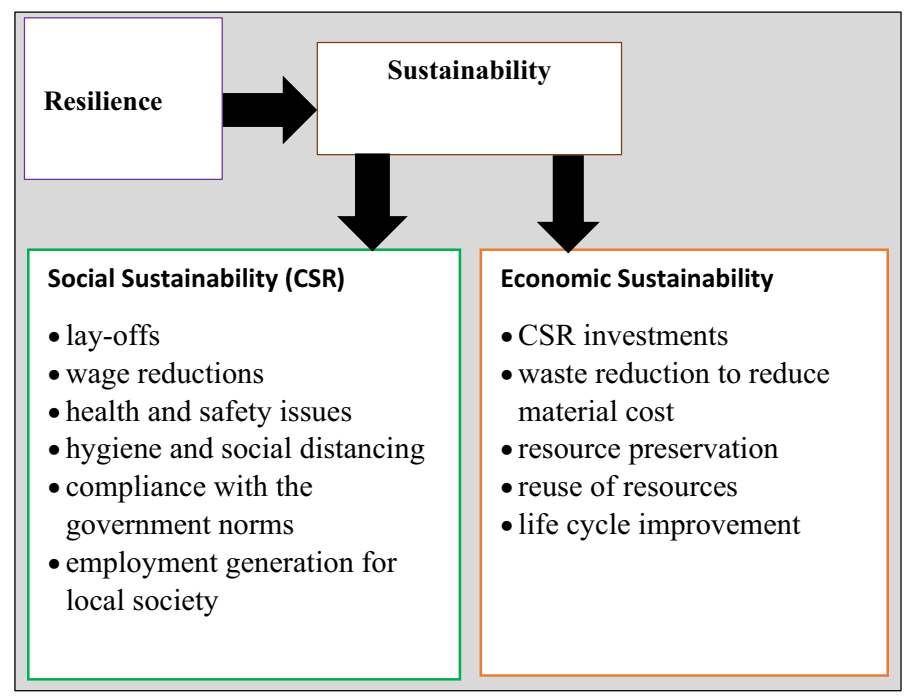

Fig. 1 Sustainability framework for resilience 
upgrading (Jia et al. 2018; Marchi et al. 2013) to value addition, GDP contribution, environmental protection, ethical investments, resource conservation, resource reuse, resource recycling and waste reduction (Zhong and Wu 2015; Manca 2015). A group of researchers also emphasizes on taking economic sustainability as economic feasibility assessment of the sustainability initiatives in any of the environmental or social dimensions which create a balance between organizational interests and sustainable responsibilities (Lovarelli et al. 2020). For instance, Tusso-Pinzón et al. (2020) have added the metrics of economic assessment as utility costs, purchase costs and profits etc. with the indicators of sustainability assessment. In the light of the current crisis, the major constructs of economic sustainability in this study are CSR investments, waste reduction to reduce material cost, resource preservation, reuse of resources and life cycle improvement (Zhong and Wu 2015; Manca 2015; Kibert 2016; Jia et al. 2018; Yazan et al. 2017; Azapagic and Perdan 2000) (see Fig. 1).

\subsection{Organizational resilience}

Resilience refers to a firm's capability to survive, adapt and grow in a dynamic and uncertain environment (Fiksel 2006; Sawik 2013). The concept of resilience refers to its capability of returning to a stable state after facing a disruptive situation. Disruptions are inevitable and there are several factors of the internal and external environment which cause disruptions in the organizations. When discussed resilience, the major concern is given to the organizational vulnerability, disruptions, and the complexities as these are the key issues dealing with the resilience of the system. Sheffi (2007), describes vulnerability to a disruptive event as a combination of the likelihood of disruption and its potential severity. The vulnerability is assessed by the probability of what can go wrong, the likelihood of that happening and the consequences of the happening. There are various dimensions of vulnerability. Low disruption probability with light consequences will cause low vulnerability while high disruption probability with severe consequences will result in high vulnerability. Christopher and Peck (2004), describe the risks which make a value chain vulnerable. The major risks are divided into five kinds of disruptions into three broad categories. The first category is related to the internal disruptions in the firm which include disruptive events during the process and control. The second group is external to the firm but internal to the supply chain consisting of disruptions in demand and supply. The third category refers to the external environment. The external environment may directly have its impact upon the players involved in the supply chain as well as the market conditions. Disruptions contain the potential to cause damages both in the short term and long term to sales, shareholders' values and status including the damage to relationships between the customers and suppliers (Bode and Wagner 2015; Hendricks 2003; Sheffi 2007). Disruptions can be defined as unplanned and unanticipated discreet events involving minimum two levels of the supply chain, but heterogeneous in characteristics which disrupt the usual courses of actions, material and goods' flows, make the firms vulnerable to the operational and financial risks and results in losses to the affected firms (Bode and Wagner 2015; Bode et al. 2011; Craighead 2007; Rao and Goldsby 2009). Bode and Wagner (2015), conclude that disruptions will increase with increasing organizational complexities as a result of interactions among more elements in the chain.

Sajko et al. (2020) describe resilience as the ability to anticipate, avoid, and adjust to shocks occurred from a crisis or a disruption. Sheffi (2007) stresses that a resilient enterprise is prepared enough to absorb the shocks of disruption and it is capable enough to 
recover from a crisis. The first ability of a resilient organization to anticipate the risks which can strike the organization in future. Anticipation starts with the collection of details of the smallest of disruptions at the organizational level and it strengthens with sharing the details among the organizations to predict the upcoming larger disruptions (Sheffi 2005). Information gathering and sharing is a key element to predict risks and build preparedness for unforeseen events and stabilize the sustainability structure (Sheffi 2005). Therefore, we hypothesize the following (see Fig. 2):

H1a Crisis anticipation will have a positive impact on social sustainability.

H1b Crisis anticipation will have a positive impact on economic sustainability.

After anticipation, the next aspect of resilience is organizational robustness which we can term as its immunity towards the disruption. Robustness has been described by the authors as a capability to be proactive to build the risk management infrastructure and become adaptive to the changes to minimize the impacts of the disruptive crisis (Chowdhury and Quaddus 2017; Soni et al. 2014; Ambulkar et al. 2015; Brusset and Teller 2017). Sheffi (2005) have emphasized on building capabilities and being prepared to mitigate the crisis and to sustain for longer. Hence, the hypothesis follows (see Fig. 2):

$\mathrm{H} 2 \mathrm{a}$ Organizational robustness will have a positive impact on social sustainability.

H2b Organizational robustness will have a positive impact on economic sustainability.

The final stage of resilience is a recovery which represents the organizational capabilities to be able to restore the system to either the previous state or to an improved state (Chowdhury and Quaddus 2017; Brusset and Teller 2017; Pettit et al. 2013; Christopher and Peck 2004). Brusset and Teller (2017) have described the capabilities as a set of physical, financial, human, technological, and organizational resources which can respond to the disruptions and accelerate the recovery process. Ambulkar et al. (2015) have pointed

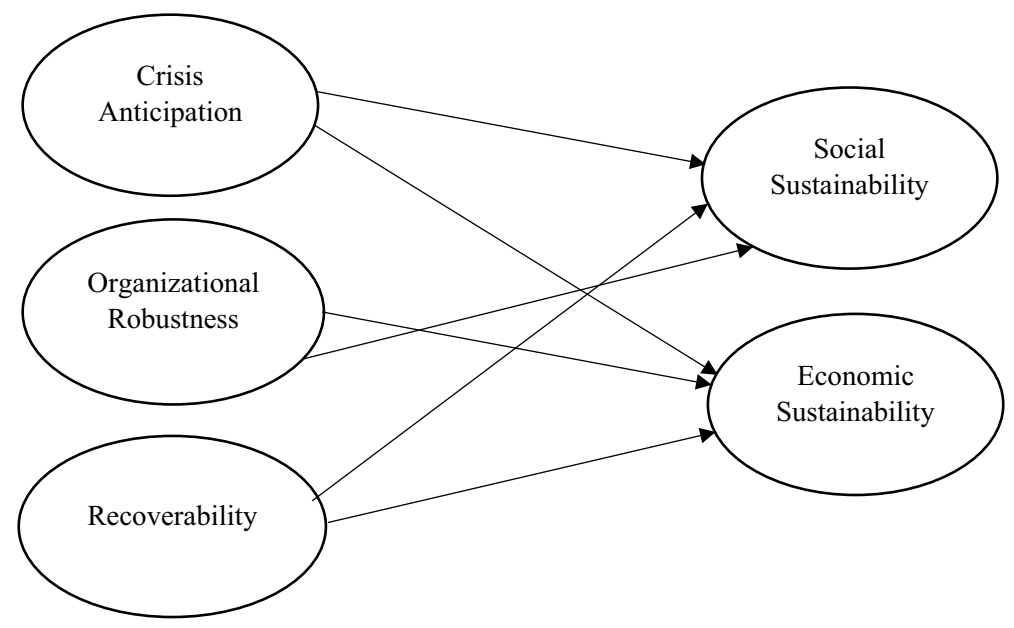

Fig. 2 Hypothesized framework 
out the ability to resource reconfiguration as a major ability of supply chains for resilience which is considered as a combination of flexibility and responsiveness to meet the changing requirement of the resources. Brusset and Teller (2017) have also backed the theory with their classification of flexibility as one of the major capabilities to mitigate risk and build resilience. Chowdhury and Quaddus (2017) along with other researchers in the area have emphasized on responsiveness and agility as major aspects of reactive organizational resilience (Hosseini et al. 2019; Soni et al. 2014; Christopher and Peck 2004). Therefore, we propose the following hypothesis (see Fig. 2):

H3a Recoverability will have a positive impact on social sustainability.

H3b Recoverability will have a positive impact on economic sustainability.

\section{Methodology}

\subsection{Research design}

The research has been conducted in India to ensure the emerging economy perspective. Current research follows an empirical analysis of primary quantitative data which is collected based on an extensive survey technique via a structured questionnaire which was sent to the companies from multiple industries doing their operations in India (see Table 1). Having taken into consideration of the current situation where direct contact is not safe, the entire data were collected online through a well-designed questionnaire. The questionnaire was designed based on the existing literature complying with current requirement during the crisis and duly verified by a set of experts for its relevance in the current situation. The questionnaires were sent electronically through emails to over 700 people and after rigorous follow-ups; we received a total number of 261 complete responses which we have considered appropriate to be used in our study. The sample consists of 146 male and 115 females. Further, the data were classified into 3 categories according to the managerial

Table 1 Respondents characteristics

\begin{tabular}{lll}
\hline Industry & Male & Female \\
\hline Textile industry & 45 & 35 \\
Electronics industry & 34 & 26 \\
Hospitality industry & 23 & 28 \\
FMCG industry & 44 & 26 \\
& $(146)$ & $(115)$ \\
Total & 261 & \\
Managerial level & & \\
Top management & 55 & \\
Middle management & 135 & \\
Lower management & 71 & \\
Total & 261 & \\
Company profile (percentage-wise) & & \\
(Firms less than 100 employees) & $60 \%$ & \\
(Firms more than 100 employees) & $40 \%$ & \\
\hline
\end{tabular}


position of the employees 55 belonged to top management, 135 middle management and 71 belonged to lower management. $60 \%$ of the firms that participated in the study belonged to a small-scale firm category and the rest $40 \%$ belonged to medium and large firm category. A complete profile of respondents in terms of industry and the hierarchy of management is available in Table 1.

\subsection{Questionnaire and measurement scale}

While preparing the questionnaire, we have focused on making it clear, easy and well written. We have chosen easy sentences and simple words to make the questionnaire more understandable. The survey questionnaire consists of five essential constructs including three constructs of resilience-crisis anticipation, organizational robustness, and recoverability; and two constructs of sustainability - social sustainability and economic sustainability. The five constructs included their defining variables that explained and formed the constructs. The construct items in the questionnaire are developed on a 7-point Likert scale. Respondents were asked to measure their responses for every construct and rate them on the given scale where 1 pertains to strongly disagree and 7 pertains to strongly agree. Once the questionnaire was finalized, we consulted the experts and sought their reviews before sending it to the respondents (refer to Table 2).

SPSS and IBM AMOS software were used to purify and analyse the data. Descriptive analysis, exploratory factor analysis (EFA), confirmatory factor analysis (CFA), structural equation modelling (SEM) tests were carried out to test the structure of the model and to check the hypotheses. After gathering the responses, the data were checked for any missing values and outliers. There were 9 missing values found and they were replaced by using missing data imputation technique in SPSS. Then, we checked the data for normality. Kurtosis and skewness tests were performed to check normality and the result of both the tests came within the permissible limit, i.e. between - 1.96 and +1.96 (Malhotra and Dash 2016). Once the data normality achieved descriptive statistics and EFA were carried out by using SPSS. After EFA, the reliability and validity of the measurement model were checked using CFA. After that measurement invariance were computed using SEM (Hair et al. 2006).

\subsection{Descriptive statistics}

In this research, a descriptive statistics analysis was done to study crisis anticipation, organizational robustness, recoverability, social sustainability and economic sustainability dimensions. The minimum value was 1 and the maximum value was 7 for the items used in the study. The mean value of the items ranged from 3.39 to 5.17, and the standard deviation ranged from 0.789 to 1.758 . The analysis shows that SS2, SS3, SS4, SS9, SS7 were the biggest contributor to social sustainability. The mean value of social sustainability was dominant over economic sustainability. Social sustainability may have more value to the respondents than economic sustainability (Table 3).

\subsection{Exploratory factor analysis (EFA)}

To measure the dimensionality of the constructs measured in this research, an EFA test was carried out using SPSS 20 statistics software. KMO test was carried out to check the adequacy of the samples and the value came as 0.854 which is well above the threshold limit 
Table 2 Questionnaire items

\begin{tabular}{ll}
\hline Variables & Items \\
\hline Social sustainability & \\
SS2 & We pay fair wages to our manpower \\
SS1 & We have not laid-off workers during the lockdown \\
SS4 & We invest in our workers' health and safety even during the crisis \\
SS3 & We have not reduced the salaries of our employees during the crisis \\
SS5 & We ensure our employees for health issues \\
SS6 & We focus on protecting our workers' rights \\
SS7 & We comply with hygiene and social distancing norms \\
SS8 & We educate and train our employees for new safety requirements \\
SS9 & We focus on job creation for local and economically, affected society
\end{tabular}

Organizational robustness

ROB1

ROB2

ROB4

ROB3

ROB5

ROB6

Recoverability

REC1

REC2

REC4

REC3

REC5

REC6

REC7

Crisis anticipation

ANTI1

ANTI2

ANTI3

ANTI4

ANTI5

ANTI6

Economic sustainability

ECOS1

ECOS2

ECOS 3

ECOS6

ECOS5

ECOS4
We are prepared enough to manage the predictable challenges

We have the preparedness to overcome the unknown challenges

We prepared ourselves when news of pandemic came out

The current has not affected our operations very much

We have maintained a supply network during the crisis

We can fulfil our customer requirements without disruption

We are recovering from the losses that occurred during pandemic and lockdown

We are flexible enough to find out to cope with the changing market requirements

We can redesign our offerings according to changing requirements

We are able to arrange alternative sources to minimize supply disruptions

We are able to respond faster to the changes

We have flexible manpower that can cope up with changes

We collaborate with other organizations to speed up the recovery process

We are able to forecast the regular disruption to operations

We collect the data of even small disruptions

We share the disruption data with other organizations

We invest in an information system that can predict the upcoming turbulence

We were able to predict the crisis before it had hit our operations

We were able to anticipate the upcoming challenges when the pandemic was at a very early stage

We invest in CSR without hurting our profits

We minimize waste to reduce our material cost

We sustainably procure and preserve the materials to increase their lifecycle

We reduce resource consumption for sustainability

We reuse resources to reduce our costs

We invest in quality for the increased life cycle of products 
Table 3 Descriptive statistics

\begin{tabular}{|c|c|c|c|}
\hline \multicolumn{4}{|l|}{ Descriptive statistics } \\
\hline & $N$ & Mean & Std. deviation \\
\hline REC7 & 261 & 4.433 & 1.4197 \\
\hline REC1 & 261 & 4.299 & 1.3166 \\
\hline REC4 & 261 & 4.322 & 1.4610 \\
\hline REC5 & 261 & 4.475 & 1.4769 \\
\hline REC3 & 261 & 4.874 & 1.4529 \\
\hline REC2 & 261 & 4.709 & 1.3698 \\
\hline REC6 & 261 & 4.973 & 1.2812 \\
\hline ECOS6 & 261 & 3.43 & .911 \\
\hline ECOS5 & 261 & 3.51 & .853 \\
\hline ECOS3 & 261 & 3.53 & .892 \\
\hline ECOS1 & 261 & 3.55 & .946 \\
\hline ECOS4 & 261 & 3.43 & .789 \\
\hline ECOS2 & 261 & 3.39 & .869 \\
\hline ANTI5 & 261 & 3.93 & 1.088 \\
\hline ANTI2 & 261 & 3.93 & 1.004 \\
\hline ANTI3 & 261 & 3.82 & .920 \\
\hline ANTI4 & 261 & 3.84 & .958 \\
\hline ANTI1 & 261 & 3.76 & .898 \\
\hline ANTI6 & 261 & 3.874 & 1.0576 \\
\hline ROB3 & 261 & 5.172 & 1.7312 \\
\hline ROB2 & 261 & 5.004 & 1.6443 \\
\hline ROB5 & 261 & 4.667 & 1.6361 \\
\hline ROB4 & 261 & 4.759 & 1.7583 \\
\hline ROB1 & 261 & 5.057 & 1.6573 \\
\hline ROB6 & 261 & 4.931 & 1.7015 \\
\hline SS1 & 261 & 4.969 & 1.3152 \\
\hline $\mathrm{SS} 2$ & 261 & 5.107 & 1.2481 \\
\hline SS3 & 261 & 5.069 & 1.3225 \\
\hline SS4 & 261 & 5.134 & 1.3277 \\
\hline SS8 & 261 & 4.372 & 1.4530 \\
\hline SS9 & 261 & 5.169 & 1.2809 \\
\hline SS5 & 261 & 4.782 & 1.3453 \\
\hline SS6 & 261 & 4.667 & 1.4223 \\
\hline SS7 & 261 & 5.008 & 1.3214 \\
\hline Valid $N$ (list wise) & 261 & & \\
\hline
\end{tabular}

of 0.5 prescribed by Hair et al. (2006). Bartlett test of sphericity was carried out to check whether the correlation exists among the variables and the values were found significant ( $p$-value $=0.000)$ (Hair et al. 2006). EFA proposed 5 factors having eigenvalue greater than 1. These factors in total explained more than $68 \%$ variance in the study. To measure the reliability of each factor Cronbach's Alpha value was observed crisis anticipation (0.897), organizational robustness (0.958), recoverability (0.918), social sustainability (0.931) and economic sustainability (0.830). The Cronbach's Alpha values were found above the threshold limit of 0.6 as recommended by Hair et al. (2006) (Table 4). 
Table 4 Exploratory factor analysis, KMO and Bartlett's Test, Cronbach's alpha

\begin{tabular}{|c|c|c|c|c|c|}
\hline \multicolumn{6}{|c|}{ Rotated component matrix ${ }^{a}$} \\
\hline \multirow{2}{*}{$\begin{array}{l}\text { KMO (.854) } \\
\text { Sig. .000 }\end{array}$} & \multicolumn{5}{|l|}{ Component } \\
\hline & $\begin{array}{l}\text { Social sus- } \\
\text { tainability }\end{array}$ & $\begin{array}{l}\text { Organizational } \\
\text { robustness }\end{array}$ & Recoverability & $\begin{array}{l}\text { Crisis } \\
\text { anticipation }\end{array}$ & $\begin{array}{l}\text { Economic } \\
\text { sustainability }\end{array}$ \\
\hline $\mathrm{SS} 2$ & .877 & & & & \\
\hline SS1 & .869 & & & & \\
\hline SS4 & .866 & & & & \\
\hline SS3 & .863 & & & & \\
\hline SS5 & .834 & & & & \\
\hline SS6 & .798 & & & & \\
\hline SS7 & .780 & & & & \\
\hline SS8 & .728 & & & & \\
\hline SS9 & 600 & & & & \\
\hline ROB1 & & .941 & & & \\
\hline ROB2 & & .935 & & & \\
\hline ROB4 & & .911 & & & \\
\hline ROB3 & & .901 & & & \\
\hline ROB5 & & .873 & & & \\
\hline ROB6 & & .870 & & & \\
\hline REC1 & & & .862 & & \\
\hline REC2 & & & .857 & & \\
\hline REC4 & & & .837 & & \\
\hline REC3 & & & .830 & & \\
\hline REC5 & & & .824 & & \\
\hline REC6 & & & .767 & & \\
\hline REC7 & & & .749 & & \\
\hline ANTI1 & & & & .862 & \\
\hline ANTI2 & & & & .833 & \\
\hline ANTI3 & & & & .828 & \\
\hline ANTI4 & & & & .803 & \\
\hline ANTI5 & & & & .798 & \\
\hline ANTI6 & & & & .749 & \\
\hline ECOS 1 & & & & & .785 \\
\hline ECOS2 & & & & & .748 \\
\hline ECOS3 & & & & & .746 \\
\hline ECOS6 & & & & & .707 \\
\hline ECOS5 & & & & & .706 \\
\hline ECOS4 & & & & & .694 \\
\hline Cronbach's alpha $(\alpha)$ & .931 & .958 & .918 & .897 & .830 \\
\hline
\end{tabular}

Extraction Method: Principal Component Analysis. Rotation Method: Varimax with Kaiser Normalization. Rotation converged in 5 iterations 


\subsection{Confirmatory factor analysis}

After EFA, CFA were carried out using AMOS graphics 20 software. The CFA results indicated a good model fit $\left(\chi^{2}=1016.681, p<0.05\right.$, df $\left.=517\right)$, reporting adequate goodness (i.e. $\mathrm{NFI}=0.85, \mathrm{CFI}=0.92)$ and badness of fit indexes $(\mathrm{RMSEA}=0.06)$. Once the model fit was achieved, the reliability of the model was inspected by computing composite reliability. All the factors scored more than 0.70 which is the standard for the composite reliability (Hair et al. 2006). After that convergent validity was checked by using the average variance extracted method as suggested by Malhotra and Dash (2016). AVE value was greater than 0.50 for all the factors. AVE was, followed by discriminant validity analysis. It is computed by checking whether the square root of the average variance extracted was greater than the correlation coefficients as suggested by Malhotra and Dash (2016), and this condition was also fulfilled (Tables 5, 6, 7).

Table 5 Measurement modelgoodness of fit measures

\begin{tabular}{llllll}
\hline CMIN & DF & CMIN/DF & CFI & NFI & RMSEA \\
\hline $1016.681^{* *}$ & 517 & 1.967 & .921 & .852 & .061 \\
$846^{* *}$ & 470 & 1.80 & .918 & .850 & .053 \\
\hline
\end{tabular}

$* *(p<0.05)$

Table 6 Construct validity

\begin{tabular}{lccccccccc}
\hline & CR & AVE & MSV & Max $R(H)$ & ANTI & SS & ROB & REC & ECOS \\
\hline Crisis anticipation & 0.901 & 0.603 & 0.051 & 0.908 & 0.777 & & & & \\
Social sustainability & 0.933 & 0.611 & 0.007 & 0.946 & 0.045 & 0.781 & & & \\
Organizational robustness & 0.955 & 0.781 & 0.007 & 0.974 & -0.002 & -0.082 & 0.884 & & \\
Recoverability & 0.919 & 0.620 & 0.006 & 0.924 & -0.046 & 0.028 & 0.078 & 0.787 & \\
Economic sustainability & 0.831 & 0.596 & 0.051 & 0.837 & 0.226 & 0.003 & -0.073 & 0.024 & 0.772 \\
\hline
\end{tabular}

Table 7 Hypotheses testing

\begin{tabular}{lllc}
\hline Effects & & Estimate & $t$-value \\
\hline $\mathrm{H} 2 \mathrm{a}$ & Social sustainability <- Robustness & $0.40^{* * * *}$ & 7.69 \\
$\mathrm{H} 3 \mathrm{a}$ & Social sustainability <- Recoverability & $0.39 * * *$ & 3.42 \\
$\mathrm{H} 1 \mathrm{a}$ & Social sustainability <- Crisis anticipation & $0.52^{* * * *}$ & 4.44 \\
$\mathrm{H} 2 \mathrm{~b}$ & Economic sustainability <- Robustness & $0.56^{* * *}$ & 5.89 \\
$\mathrm{H} 3 \mathrm{~b}$ & Economic sustainability<- Recoverability & $0.41^{* * *}$ & 4.22 \\
$\mathrm{H} 1 \mathrm{~b}$ & Economic sustainability <-Crisis anticipation & $0.45^{* * *}$ & 3.38 \\
\hline
\end{tabular}

$* * * p<0.001$ 


\subsection{Structural equation modeling and hypotheses testing}

After obtaining an acceptable model fit, a structural model was built based on the proposed hypotheses. The model fit indices found that the hypothesis model fits the data well. The regression weights confirm our hypotheses. Hypotheses used in this study were found significant. The path coefficients (H2a-0.40, H3a- 0.39, H1a- 0.52, H2b- 0.56, H3b- 0.41, H1b- 0.45), validate the applicability of the sustainability model.

\section{Findings and discussion}

Results describe the positive impact of determinants of resilience on the social and economic sustainability. It explains that in case if the organization is resilient the social values of the economy will more likely to sustain and there are high chances the economic investments in the conservation of resources and sustainable production will increase. The study finds out that capability to anticipate crisis has a positive effect on social and economic sustainability. It stresses on a collaborative inter-organizational and intraorganizational information sharing mechanism on a large scale where the smallest of crises can be recorder and shared among each other to predict a bigger crisis (Sheffi 2005). The study suggests that prediction of a crisis on a collaboration basis provides a more resilient organisational structure where organizations establish and maintain their resources including material, money and human resources. There are high chances if the organizations can anticipate the crisis in advance, and they will sustainably preserve the resources as well they will display the stability in maintaining the social values which include the rights of their employees.

Organizations which are more prepared and show more robustness are more immune to the crisis. However, the robustness comes from the readiness to confront and survive the crisis which depends on the resources the organization has preserved and the manpower it has sustainably secured (Sheffi 2005; Ambulkar et al. 2015; Brusset and Teller 2017). The study finds out the positive impact of organizational robustness on the social and economic sustainability. It can be because a resilient organization needs to maintain its resources and keep its costs lower which is easier if it adopts a sustainable approach of waste reduction, resource preservation, social development and human resource sustainability. Recoverability is the final aspect of resilience which has its positive effect on social and economic sustainability which is because the recovery requires the ability to reconfigure the resources, agility to respond to the requirements and flexibility to adapt to the changes (Chowdhury and Quaddus 2017; Ambulkar et al. 2015; Brusset and Teller 2017). A sustainable approach in all the aforementioned situations is required where both the employer and employees can rely on each other as well as they can maintain sustainable values.

\subsection{Combined approach of sustainable resilience}

The study finds out the positive impact resilience on sustainability. It observes the corresponding nature of both the principles for each other when it concerns about the social principles and recovery of the society from a crisis situation. A sustainable and resilient organization brings in the diversity, connectivity, learning social participation and 
Fig. 3 Sustainability-resilience matrix

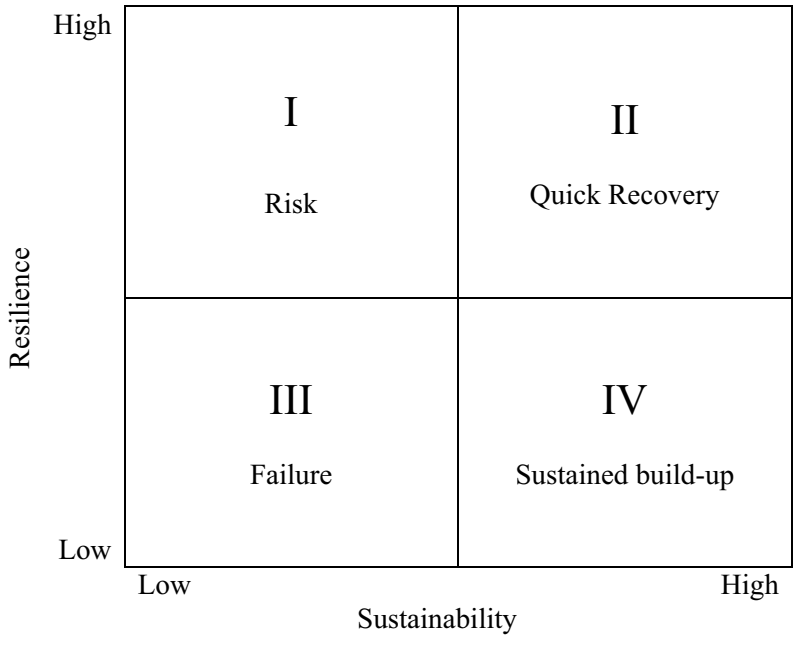

inclusive policy making which survives in and recovers from the crisis without compromising its sustainable value (Choi et al. 2021; Shamout et al. 2021). To make the discussion of the findings and observations more comprehensive, the study provides a sustainability- resilience matrix (see Fig. 3) where we compare the different levels of resilience and sustainability with each other. The first quadrant presents a situation where resilience is high, and sustainability is low. Although a resilient situation seems to be under control, but without the sustainable values it will be a risky situation when the robustness of the organization reaches its limits and the firm requires to recover. A contradiction with the social values and a negative social image may derail the desired speed of the entire recovery process. The second quadrant represents a high resilience and high sustainable situation which keeps the organization fundamentally correct on both the fronts which will speed up the recovery process. In the third quadrant, we find that the organization is neither sustainable nor resilient which make it destined to fail whenever a crisis occurs which cannot be either avoided or controlled. The fourth quadrant presents the combination of low resilience but high sustainability situation. The situation is more relevant to a large-scale crisis scenario where the reserved contingency plans of the organization's end, robustness fails and crisis overtakes. In this scenario, the organizations which are fundamentally correct with sustainable principles, seem to build up stronger and fight back more efficiently.

In Fig. 4, we provide a holistic view of sustainability and resilience where both aspects complement each other. The outer circle represents resilience and its different aspects, the innermost side of the circle represents the social and economic sustainability which has its determinants on the outer side. The resilience-sustainability circle represents a framework which explains that an organization requires to build up resilience to stabilize its sustainability structure. As shown in the outer circle, the resilience capabilities of an organization lead to the individual initiatives of sustainable development and when it is combined in a collective approach it leads to the overall social and economic sustainability development. 


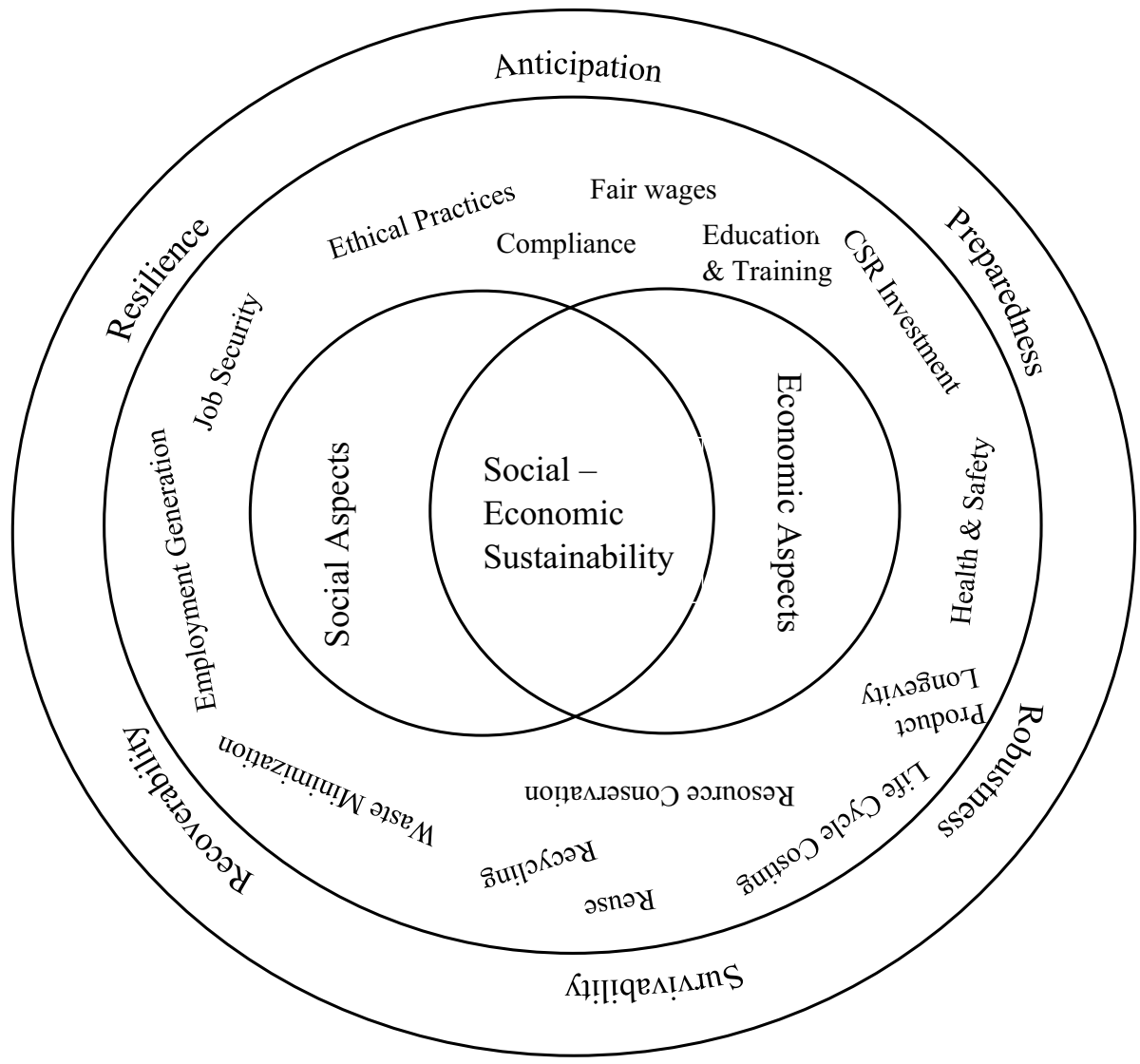

Fig. 4 Sustainability-resilience framework

\section{Conclusion}

The current study attempts to develop a conceptual framework for organization resilience which can sustain the social and economic values and contribute to the overall sustainable development. It argues that building organizational resilience is a way to maintain the social and economic sustainability structure in terms of the development of society, the welfare of the manpower social security, resource conservation and environmental protection, while maintaining the profitability and cost structure of the firm. The study has assessed the effectiveness of various aspects of resilience amid the impact of these aspects on the sustainable practises in the typically functioning organizational operations. The interaction between resilience and sustainability discloses the specific insights from relationships to the researchers and practitioners. The study contributes to both industry and academia in many ways. Firstly, it identifies the specific social and economic sustainability constructs from an organizational perspective considering the current COVID-19 crisis. Secondly, the study conceptually discovers the major constructs for organizational resilience which may affect its sustainability at any stage. The constructs are crucial considering the current crisis, if not defined properly they may provide vague results. Thirdly, the 
study produces a comprehensive framework for the aspect wise investigation of resilience for sustainability within the impactful construct interactions. The study has clear managerial and theoretical implications for both practitioners and the research community. The framework for the aspect wise evaluation of resilience in the current research provides a theoretical foundation for researchers to establish a micro-level sustainability analysis approach. Focus on aspect specific resilience constructs provides detailed insights towards identifying and prioritizing the key determinants crucial to the individual stages of sustainability. The research has some social implications as well. It provides researchers and practitioners with a framework for better utilization of resources and maintaining social values which is important for social and sustainable development.

There are certain limitations associated with the current research which provide the research gap for future study. First, the study has focused only on the social and economic aspects of sustainability. However, a more comprehensive approach with a triple bottom line approach which includes environmental aspects also would provide a more holistic view of the resilience-sustainability relationship. Second, the study focuses on three-dimensional aspects of resilience which include crisis anticipation, organizational robustness and recoverability to assess a cause and effect relationship with sustainability. A mathematical modelling and analysis approach with the evaluation of trade-offs among resilience aspects and simultaneous trade-off analysis among sustainability dimensions may yield more comprehensive results. Third, the study was carried during COVID-19 outbreak resulting in country-wide lock-down with high restrictions, and reaching to more respondents was very difficult. Although we used an electronic medium for sending and receiving the questionnaires, it was not easy for the respondents as well. For the future, we suggest implementing the current methodology with the inclusion of additional constructs, once the COVID-19 situation comes under control to observe the current findings during the recovery period. Fourth, the study has considered only the quantitative aspects of sustainability-resilience assessment. For future studies, we suggest the inclusion of a more comprehensive qualitative analysis to cover the aspects which do not get covered in the quantitative analysis.

\section{References}

Ambulkar, S., Blackhurst, J., \& Grawe, S. (2015). Firm's resilience to supply chain disruptions: Scale development and empirical examination. Journal of operations management, 33, 111-122.

Arora, A. S., Rajput, H., Changotra, R. (2020). Current perspective of COVID-19 spread across South Korea: Exploratory data analysis and containment of the pandemic. Environment, development and sustainability, 1-11.

Azapagic, A., \& Perdan, S. (2000). Indicators of sustainable development for industry: A general framework. Process Safety and Environmental Protection, 78(4), 243-261.

Barbosa-Póvoa, A. P., da Silva, C., \& Carvalho, A. (2018). Opportunities and challenges in sustainable supply chain: An operations research perspective. European Journal of Operational Research, 268, 399-431.

Bherwani, H., Nair, M., Musugu, K., Gautam, S., Gupta, A., Kapley, A., Kumar, R. (2020). Valuation of air pollution externalities: Comparative assessment of economic damage and emission reduction under COVID-19 lockdown. Air Quality, Atmosphere \& Health, 1-12.

Bode, C., \& Wagner, S. M. (2015). Structural drivers of upstream supply chain complexity and the frequency of supply chain disruptions. Journal of Operations Management, 36, 215-228.

Bode, C., Wagner, S. M., Petersen, K. J., \& Ellram, L. M. (2011). Understanding responses to supply chain disruptions: Insights from information processing and resource dependence perspectives. Academy of Management Journal, 54(4), 833-856. 
Brusset, X., \& Teller, C. (2017). Supply chain capabilities, risks, and resilience. International Journal of Production Economics, 184, 59-68.

Cairns, R. D., \& Martinet, V. (2014). An environmental-economic measure of sustainable development. European Economic Review, 69, 4-17.

Chelan, M. M., Alijanpour, A., Barani, H., Motamedi, J., Azadi, H., \& Van Passel, S. (2018). Economic sustainability assessment in semi-steppe rangelands. Science of the Total Environment, 637, 112-119.

Choi, Y. E., Oh, C. O., \& Chon, J. (2021). Applying the resilience principles for sustainable ecotourism development: A case study of the Nakdong Estuary, South Korea. Tourism Management, 83, 104237.

Chowdhury, M. M. H., \& Quaddus, M. (2017). Supply chain resilience: Conceptualization and scale development using dynamic capability theory. International Journal of Production Economics, $188,185-204$.

Christopher, M., \& Peck, H. (2004). Building the resilient supply chain. The International Journal of Logistics Management, 15(2), 1-14.

Clark, W. C. (2007). Sustainability science: A room of its own. Proceedings of the National Academy of Sciences, 104(6), 1737-1738.

Clark, W. C., \& Dickson, N. M. (2003). Sustainability science: The emerging research program. Proceedings of the National Academy of Sciences, 100(14), 8059-8061.

Craighead, C. W. (2007). The severity of supply chain disruptions: Design characteristics and mitigation capabilities. Decision Sciences, 38(1), 131-156.

Esfahbodi, A., Zhang, Y., \& Watson, G. (2016). Sustainable supply chain management in emerging economies: trade-offs between environmental and cost performance. International Journal of Production Economics, 181, 350-366.

Fiksel, J. (2006). Sustainability and resilience: Toward a systems approach. Sustainability: Science, Practise, Policy, 2(2), 14-21.

Gautam, S. (2020). The influence of COVID-19 on air quality in India: A boon or inutile. Bulletin of Environmental Contamination and Toxicology, 1.

Gautam, S., Hens, L. (2020). COVID-19: Impact by and on the environment, health and economy.

Gupta, P. (2020, May 13). How Maggi, KitKat supplies didn't stop during lockdown; why coronavirus failed to hurt Nestle. Financial Express. Retrieved from https://www.financialexpress.com/industry/ nestle-india-q1-results-fmcg-coronavirus-lockdown-supply-chain-maggi-munch-kitkat-nestle-q1earnings/1957430/.

Hendricks, K. B. (2003). The effect of supply chain glitches on shareholder wealth. Journal of Operations Management, 21, 501-522.

Hair, J. F., Black, W. C., Babin, B. J., Anderson, R. E., \& Tatham, R. (2006). Multivariate data analysis. Uppersaddle River, NewJersy: Pearson Education Ltd.

Hosseini, S., Ivanov, D., \& Dolgui, A. (2019). Review of quantitative methods for supply chain resilience analysis. Transportation Research Part E: Logistics and Transportation Review, 125, 285-307.

Jia, F., Zuluaga-Cardona, L., Bailey, A., \& Rueda, X. (2018). Sustainable supply chain management in developing countries: An analysis of the literature. Journal of Cleaner Production, 189, 263-278.

Kates, R. W., Clark, W. C., Corell, R., Hall, J. M., Jaeger, C. C., Lowe, I., \& Faucheux, S. (2001). Environment and development. Sustainability science. Science (New York, NY), 292(5517), 641-642.

Kibert, C. J. (2016). Sustainable construction: Green building design and delivery. New Jersey: Wiley.

King, A. A., \& Lenox, M. J. (2001). Lean and green? An empirical examination of the relationship between lean production and environmental performance. Production and Operations Management, 10(3), 244-256.

Lovarelli, D., Bacenetti, J., Guarino, M. (2020). A review on dairy cattle farming: Is precision livestock farming the compromise for an environmental, economic and social sustainable production?. Journal of Cleaner Production, 121409.

Malhotra, N. K., \& Dash, S. (2016). Marketing research (7th ed.). New Delhi: Pearson Education Ltd.

Manca, D. (2015). Economic sustainability of products and processes. In Computer Aided Chemical Engineering (Vol. 36, pp. 615-642). Amsterdam: Elsevier.

Mani, V., Gunasekaran, A., Papadopoulos, T., Hazen, B., \& Dubey, R. (2016). Supply chain social sustainability for developing nations: Evidence from India. Resources, Conservation and Recycling, $111,42-52$.

Mani, V., Gunasekaran, A., \& Delgado, C. (2018). Supply chain social sustainability: Standard adoption practises in Portuguese manufacturing firms. International Journal of Production Economics, 198, 149-164.

Marchi, V. D., Maria, E. D., \& Micelli, S. (2013). Environmental strategies, upgrading and competitive advantage in global value chains. Business strategy and the environment, 22(1), 62-72. 
Pettit, T. J., Croxton, K. L., \& Fiksel, J. (2013). Ensuring supply chain resilience: Development and implementation of an assessment tool. Journal of business logistics, 34(1), 46-76.

Pires, A., Morato, J., Peixoto, H., Botero, V., Zuluaga, L., \& Figueroa, A. (2017). Sustainability assessment of indicators for integrated water resources management. Science of the total environment, $578,139-147$.

Qorri, A., Mujkic, Z., \& Kraslawski, A. (2018). A conceptual framework for measuring sustainability performance of supply chains. Journal of Cleaner Production, 189, 570-584.

Rajput, H., Changotra, R., Rajput, P., Gautam, S., Gollakota, A. R., \& Arora, A. S. (2020). A shock like no other: Coronavirus rattles commodity markets. Environment, Development and Sustainability, $1-12$.

Rao, S., \& Goldsby, T. J. (2009). Supply chain risks: A review and typology. The International Journal of Logistics Management, 20(1), 97-123.

Sajko, M., Boone, C., Buyl, T. (2020). CEO greed, corporate social responsibility, and organizational resilience to systemic shocks. Journal of Management, 0149206320902528.

Sawik, T. (2013). Selection of resilient supply portfolio under disruption risks. Omega, 41, 259-269.

Shamout, S., Boarin, P., Wilkinson, S. The shift from sustainability to resilience as a driver for policy change: A policy analysis for more resilient and sustainable cities in Jordan. Sustainable Production and Consumption, 25, 285-298.

Sharma, A., Gupta, P., \& Jha, R. (2020). COVID-19: Impact on health supply chain and lessons to be learnt. Journal of Health Management, 22(2), 248-261.

Sheffi, Y. (2007). The resilient enterprise: Overcoming vulnerability for competitive advantage. Cambridge, Massachusetts: MIT Press.

Sheffi, Y., \& Rice, J. B., Jr. (2005). A supply chain view of the resilient enterprise. MIT Sloan management review, $47(1), 41$.

Soni, U., Jain, V., \& Kumar, S. (2014). Measuring supply chain resilience using a deterministic modeling approach. Computers \& Industrial Engineering, 74, 11-25.

Spangenberg, J. H. (2005). Economic sustainability of the economy: Concepts and indicators. International Journal of Sustainable Development, 8(1-2), 47-64.

Tang, C. S. (2018a). "Socially responsible supply chains in emerging markets: Some research opportunities. Journal of Operations Management, 57, 1-10.

Tang, C. S. (2018b). Socially responsible supply chains in emerging markets: Some research opportunities. Journal of Operations Management, 57, 1-10.

Tusso-Pinzón, R. A., Castillo-Landero, A., Matallana-Pérez, L. G., \& Jiménez-Gutiérrez, A. (2020). Intensified synthesis for ethyl lactate production including economic, sustainability and inherent safety criteria. Chemical Engineering and Processing-Process Intensification, 154, 108041.

Yazan, D. M., Mandras, G., \& Garau, G. (2017). Environmental and economic sustainability of integrated production in bio-refineries: The thistle case in Sardinia. Renewable Energy, 102, 349-360.

Zhang, M., Tse, Y. K., Doherty, B., Li, S., \& Akhtar, P. (2018). Sustainable supply chain management: Confirmation of a higher-order model. Resources, Conservation and Recycling, 128, 206-221.

Zhong, Y., \& Wu, P. (2015). Economic sustainability, environmental sustainability and constructability indicators related to concrete-and steel-projects. Journal of Cleaner Production, 108, 748-756.

Publisher's Note Springer Nature remains neutral with regard to jurisdictional claims in published maps and institutional affiliations. 